\title{
Representações sociais elaboradas por pessoas idosas sobre ser idoso ou envelhecido: abordagens estrutural e processual
}

Social representations elaborated by elderly people about being elderly or aged: structural and procedural approaches

Representaciones sociales elaboradas por personas ancianas sobre ser mayor o envejecido: enfoque estructural y procesual

\section{Laércio Deleon de Melo', Cristina Arreguy-Sena' ${ }^{\mathrm{II}}$, Antônio Marcos Tosoli Gomes ${ }^{\mathrm{II}}$ Pedro Miguel Dinis Parreira ${ }^{\mathrm{IV}}$, Paulo Ferreira Pintov ${ }^{\mathrm{v}}$, Júlio Cézar Cruz Collares da Rocha ${ }^{\mathrm{VI}}$}

Resumo: Objetivo: discutir as representações sociais de pessoas com idade $\geq 65$ anos sobre ser idoso ou envelhecido. Método: pesquisa delineada na Teoria das Representações Sociais. Participaram idosos de uma Unidade Básica de Saúde mineira. Coletaram-se dados de caracterização sociodemográfica e foram aplicadas técnica de evocação e entrevistas gravadas, em 2015, com análises prototípica e de conteúdo, apoiadas por softwares. Resultados: participaram 93 idosos, maioria mulheres (62,4\%), com 72 anos em média e escolaridade $\leq 8$ anos (88,15\%). Identificaram-se conteúdos nucleares - comum: "avalia-ser-velho" e distintos: "idade-chega” e "experiência" (ser idosa) e "difícil-ruim" (ser envelhecida). Na abordagem processual, identificou-se engajamento para lidar com novas demandas, apesar do reconhecimento de limitações secundárias ao processo de envelhecimento. Conclusão: verificou-se ausência de conteúdos nucleares objetivados, sendo os comportamentos e pensamentos ancorados em experiências próprias e com terceiros, vinculados ao nível de (in)dependência, condições de vida e redes de apoio, carreando semelhanças e distinções.

Descritores: Enfermagem Geriátrica; Envelhecimento; Idoso; Psicologia Social; Cultura

Abstract: Objective: to discuss the social representations of people aged $\geq 65$ years about being elderly or aged. Method: research outlined in the Theory of Social Representations. Elderly people from Minas Gerais Basic Health

\footnotetext{
${ }^{\text {I }}$ Enfermeiro, Mestre em Enfermagem. Faculdade de Enfermagem da Universidade Federal de Juiz de Fora (FACENF-UFJF), Juiz de Fora, Minas Gerais (MG), Brasil. E-mail: laerciod128@hotmail.com ORCID: 0000-0002-8470-7040.

${ }^{\text {II }}$ Enfermeira, Doutora em Enfermagem. Faculdade de Enfermagem da Universidade Federal de Juiz de Fora (FACENF-UFJF), Juiz de Fora, Minas Gerais (MG), Brasil. E-mail: cristina.arreguy@ufjf.edu.br ORCID: 0000-0002-5928-0495.

III Enfermeiro, Doutor em Enfermagem. Faculdade de Enfermagem da Universidade Estadual do Rio de Janeiro (UERJ), Rio de Janeiro (RJ), Brasil. E-mail: mtosoli@gmail.com ORCID: 0000-0003-4235-9647.

IV Enfermeiro, Doutor em Enfermagem. Escola Superior de Enfermagem de Coimbra (Portugal). E-mail: pedromiguel.parreira@gmail.com ORCID: 0000-0002-3880-6590.

${ }^{\vee}$ Educador físico, Doutor em Educação Física. Faculdade de Educação Física e Desportos da Universidade Federal de Juiz de Fora (FAEFIDUFJF), Juiz de Fora, Minas Gerais (MG), Brasil. E-mail: paulo.ferpinto@gmail.com ORCID: 0000-0001-7321-3160.

VI Psicólogo, Doutor em Psicologia. Faculdade de Psicologia da Universidade Católica de Petrópolis (UCP), Petrópolis, Rio de Janeiro (RJ), Brasil. E-mail: juliorochapesquisa@gmail.com ORCID: 0000-0003-1611-1920.
} 
Unit participated. Sociodemographic characterization data were collected and evocation technique and recorded interviews were applied in 2015, with prototypical and content analyzes, supported by softwares. Results: 93 elderly people participated, mostly women (62.4\%), aged 72 years on average and with $\leq 8$ years of education (88.15\%). Nuclear contents were identified - common: "evaluates-being-old" and distinct: "age-arrives" and "experience" (being elderly) and "difficult-bad" (being aged). In the procedural approach, engagement to deal with new demands was identified, despite the recognition of secondary limitations to the aging process. Conclusion: there was an absence of objective nuclear contents, with behaviors and thoughts anchored in one's experiences and in other people's, linked to the level of (in)dependency, living conditions and support networks, carrying similarities and distinctions.

Keywords: Geriatric Nursing; Aging; Elderly; Social Psychology; Culture

Resumen: Objetivo: debatir las representaciones sociales que tienen personas con edad a partir de 65 años respecto a ser mayor o envejecido. Método: investigación basada en la Teoría de las Representaciones Sociales. Los participantes son ancianos de una Unidad Básica de Salud de Minas Gerais. Se recolectaron datos de caracterización sociodemográfica y se realizaron técnica de evocación y grabación de entrevistas, en 2015, con análisis prototípico y de contenido con el apoyo de softwares. Resultados: una cantidad de 93 ancianos participantes, mayoría mujeres $(62,4 \%)$, con media de 72 años de edad y a partir de ocho años de escolaridad $(88,15 \%)$. Se delimitaron contenidos nucleares comunes: “considera-ser-viejo" y “experiencia” (ser mayor) y “difícilmalo" (ser envejecido). En el enfoque procesual, se identificó compromiso para hacer frente a nuevas demandas, a pesar del reconocimiento de limitaciones secundarias al proceso de envejecimiento. Conclusión: se observó una falta de contenidos nucleares objetivos, puesto que los comportamientos y pensamientos son anclados en experiencias propias y con terceros, asociados al nivel de (in)dependencia, condiciones de vida y redes de apoyo y llevan puntos de similitudes y diferencias.

Descriptores: Enfermería geriátrica; Envejecimiento; Anciano; Psicología Social; Cultura

\section{Introdução}

Projeções sobre o envelhecimento mundial para 2030 demonstram que o número de pessoas com idade $\geq 60$ anos deve crescer 56\%; ou seja, passar de 901 milhões para 1,4 bilhão e, em 2050, alcançar 2,1 bilhões. ${ }^{1-3}$ No Brasil, a proporção de pessoas com mais de 60 anos passará de $18,7 \%$ para $28,4 \%$ e, entre aquelas com 65 ou mais, passará de $13,5 \%$ para $21,9 \%$. No período de 2030 a 2050, o índice de envelhecimento crescerá de $71 \%$ para $142,2 \%{ }^{1}$ No Ranking mundial, o Brasil será o sexto país com população com idade $\geq 60$ anos, correspondendo a 32 milhões em 2025 e 50 milhões em $2050 .^{1-2}$ 
3 | Melo LD, Arreguy-Sena C, Gomes AMT, Parreira PMD, Pinto PF, Rocha JCCC

A magnitude dessas projeções fundamenta a inserção da temática "envelhecimento humano” entre as linhas de prioridade da Agenda Nacional de Prioridades de Pesquisa em Saúde. O objetivo é o direcionamento do olhar dos profissionais de saúde e das políticas públicas às vulnerabilidades a que os idosos estão expostos. ${ }^{4}$ Tal fato justifica as previsões de busca desse segmento populacional pelos serviços de saúde e permite estimar ações de prevenção de doenças, promoção da saúde, tratamento e reabilitação de comorbidades. Evidencia-se, ainda, a necessidade de conhecimentos sobre quais são as demandas emergentes na perspectiva de grupos sociais. ${ }^{3}$

A velhice socialmente pode carrear imagens culturalmente construídas, tornando-se acessível de ser captada. ${ }^{5}$ Optou-se pelo uso concomitante das abordagens Estrutural ${ }^{6}$ e Processual $^{7}$ da Teoria das Representações Sociais (TRS) ${ }^{5,7}$ como estratégia para apreender o objeto de investigação. A justificativa da escolha envolve a compreensão de que o tema é passível de ser acessado como um componente do conhecimento psicossociológico. ${ }^{5}$ A “espessura social” do grupo se configura pela pertinência da temática para os participantes investigados.

O envelhecimento está sendo concebido como a progressão da idade, acompanhada por modificações que se expressam nas dimensões biopsicossocial, cultural e espiritual segundo autopercepção que impacta a autonomia e a independência à medida que os anos passam, de forma individualizada, progressiva, irreversível e inevitável. ${ }^{8-9}$ A lacuna científica identificada envolve as aproximações e distinções na concepção de um grupo social a respeito de ser idoso ou envelhecido, o que justifica a realização da presente investigação. Outra possibilidade envolve o retratar das representações sociais de como uma pessoa se sente nessa fase da vida a ponto de subsidiar a compreensão do enfermeiro sobre a pessoa idosa e seu contexto social. ${ }^{10}$

Considerando que a enfermagem utiliza as respostas humanas como alicerce para estruturar o cuidado e refletindo sobre sua inserção interdisciplinar no atendimento de saúde às 
pessoas idosas, surgiram as indagações: Como o processo de envelhecimento é representado por aqueles que envelhecem? Quais conteúdos e processos constitutivos alicerçam seus comportamentos, atitudes, conhecimentos, informações e valores? Que aproximações e distinções são construídas socialmente sobre “ser idoso" e "ser envelhecido"? Diante do exposto, a presente investigação objetivou discutir as representações sociais de pessoas com idade $\geq 65$ anos sobre ser idoso ou envelhecido.

\section{Método}

Trata-se de pesquisa qualitativa, com abordagens estrutural ${ }^{6}$ e processual $^{7}$ da TRS. O cenário da investigação foi uma área adstrita a uma Unidade Básica de Saúde (UBS) de um município do Estado de Minas Gerais (MG), Brasil. Essa área foi delineada a partir da coincidência entre área censitária do Instituto Brasileiro de Geografia e Estatística e a adstrita à UBS atendida pelo Programa de Agentes Comunitários de Saúde (Pacs).

Os participantes foram recrutados por convite individual em visita domiciliar, quando os pesquisadores foram apresentados pelos agentes de saúde. Pessoas com idade $\geq 65$ anos que apresentavam fala com coerência e que eram adstritas à UBS foram consideradas elegíveis. Foram excluídas aquelas que, durante a coleta, mudaram de endereço, foram a óbito ou estiveram internadas. Sendo assim, de um total de 110 idosos, um foi excluído por mudança de endereço e 16 foram considerados como perda por desistirem da participação durante a coleta de dados. Assim, 93 pessoas com idade $\geq 65$ anos participaram da pesquisa.

Apesar de no Brasil a idade $\geq 60$ anos ser o critério cronológico para considerar que uma pessoa é idosa, na presente investigação, foi realizado um recorte para $\geq 65$ anos. Tal decisão se justifica pela intensificação das características peculiares ao envelhecimento quando se acentua a divergência entre as concepções cronológica e identitária sobre o envelhecimento. ${ }^{1-3}$ 
5 | Melo LD, Arreguy-Sena C, Gomes AMT, Parreira PMD, Pinto PF, Rocha JCCC

O instrumento de coleta de dados foi estruturado em: 1) Caracterização sociodemográfica; 2) Aplicação da Técnica de Associação Livre de Palavras Desencadeadas por Imagens (TALPDI) - uso de figuras/imagens, contemplando elementos de valor neutro, positivo e negativo, previamente validadas por peritos e destinadas a pessoas idosas e com baixa escolaridade $^{11}$ - abordagem estrutural e 3) Entrevista gravada, buscando conteúdos discursivos que abordassem casos e lembranças que retratem autopercepção sobre o processo de envelhecimento, identidade, papel, experiência, saberes, participação social, rede de apoio e modificações advindas do envelhecimento - abordagem processual. Os dados foram coletados em 2015.

O processo de coleta de dados se deu por entrevista individual em domicílio. Foi operacionalizada por dois ou três encontros antecedidos pela assinatura dos participantes no Termo de Consentimento Livre e Esclarecido (TCLE), após terem sido informados sobre a pesquisa e esclarecidas suas dúvidas. O processo ocorreu na sequência apresentada no instrumento. Os dados de caracterização foram consolidados no programa Statistical Package for the Social Sciences (SPSS), versão 24 e analisados segundo estatística descritiva (medida de tendência central e dispersão).

Com o uso da técnica TALPDI na abordagem estrutural, foi solicitado ao participante que falasse as cinco primeiras palavras que lhe viessem à mente após manusear as figuras e ouvir o termo indutor "pessoa ser idosa”. Após a evocação, foi repetida a técnica, usando o termo indutor "pessoa ser envelhecida”. Os resultados foram registrados cursivamente, tendo sido os dados tratados por análise prototípica, com o software Ensemble de Programmes Permettant L'analyse des Evocations (EVOC), versão $2005 .{ }^{12} \mathrm{Na}$ análise prototípica, foram obtidas 465 palavras/expressões evocadas para cada termo indutor. Foram utilizados $63,7 \%$ e $62,4 \%$ do corpus original para os termos indutores "pessoa ser idosa" e "pessoa ser envelhecida”, o que equivaleu, respectivamente, a 116 e 109 cognemas distintos. 
$\mathrm{Na}$ abordagem Estrutural, os elementos da representação se organizam em torno de um núcleo central cujos conteúdos evocados são alocados de forma hierarquizada. O sistema central retrata elementos socialmente contextualizados para um determinado grupo e pode ser retratado no quadro de quatro casas pelas expressões alocadas no Quadrante Superior Esquerdo (QSE). Ou seja, expressões que tiveram maior frequência de citação foram evocadas nas primeiras posições, cuja Ordem Média de Evocação (OME) gerou um menor Rang. Por isso, são expressões consideradas estáveis e permanentes no contexto das representações. Isso lhes confere sentido e resistência ao processo de mudança, em função do contexto externo ou das práticas cotidianas dos sujeitos.

Outros componentes com potencial de centralidade, estão alocados no Quadrante Inferior Esquerdo (QIE), Zona de Contraste, cujos cognemas possuem menor frequência, maior Rang e menor OME. Eles foram considerados importantes para um subgrupo representacional e retratam possíveis movimentos com potencialidade de migrar para o QSE, desde que o grupo seja ampliado. ${ }^{6-7}$

Por outro lado, os componentes periféricos possibilitam captar singularidades individuais advindas de experiências particularizadas. Eles podem ser alocados na primeira periferia, Quadrante Superior Direito (QSD), por possuírem elementos com maior frequência, maior Rang e baixa OME. Eles expressam o contexto imediato no qual as pessoas vivem suas relações sociais. Por isso, possuem potencial para migrar para o núcleo central, o que lhes assegura a possibilidade de ser considerados elementos intermediários. No Quadrante Inferior Direito (QID), encontram-se os chamados elementos de segunda periferia. Nesse locus, estão os legítimos elementos periféricos do sistema por possuírem baixa frequência, Rang alto, baixa OME e importância para subgrupos representacionais na medida em que retratam condições peculiares e vivências pessoais. ${ }^{6-7}$ 
Cabe mencionar que a ligação entre os sistemas periférico e central permite a alocação de alguns elementos nas áreas de transição ou na primeira periferia. Essas áreas funcionam como sistema amortecedor capaz de conferir significado, organização aos conteúdos e estabilidade aos componentes centrais na medida em que retratam componentes socialmente consensualizados. ${ }^{6-7}$

$\mathrm{Na}$ abordagem processual, os discursos dos participantes foram lidos e analisados segundo seu conteúdo, ${ }^{13}$ empregando o programa NVivoPro-11. Foram utilizados (nós) a priori conteúdos categoriais para retratar as dimensões representacionais (comportamental e atitudinal; cognitiva e informativa; valorativa e de objetivação) e suas origens (experiências pessoais, familiares e contexto social). ${ }^{7,12}$

Tal fato permitiu captar comportamentos/atitudes, significar/ressignificar valores a partir de uma releitura da própria vida, acessar informações e conhecimentos e conceber o objeto representado a ponto de alcançar os conteúdos simbólicos. ${ }^{7,12}$ Desse modo, foi possível compreender qual a origem da representação elaborada e construída pelo grupo socialmente constituído. O critério para identificar o adensamento teórico foi o coeficiente de Pearson ${ }^{12} \operatorname{com}$ valores $\geq 0,70$, tendo sido identificados valores compreendidos entre 0,935252 e 0,715496 e entre 0,849226 e 0,755286 para “ser idoso e “ser envelhecido” respectivamente.

Foram atendidos todos os requisitos éticos e legais em pesquisa envolvendo seres humanos, conforme legislação nacional vigente. Esta investigação advém de uma pesquisa matriz, intitulada "Capacidade física, incontinências e determinantes do processo de envelhecimento de pessoas acima de 65 anos”, aprovada no Comitê de Ética em Pesquisa da Universidade Federal de Juiz de Fora (CEP/UFJF) sob o parecer consubstanciado n. 341.116, de $11 / 07 / 2013$. 


\section{Resultados}

A maioria dos 93 idosos ficou assim caracterizada: 58 (62,4\%) mulheres; com idade média 72 anos (65-96); 48 (51,6\%) se declararam da cor de pele parda; $50(53,7 \%)$ eram casadas ou viviam com companheiro; com média de quatro filhos $(0-21) ; 82(88,1 \%)$ com até oito anos de escolaridade. Quanto à profissão exercida pela maioria dos idosos, 38 (40,8\%) realizavam serviços domésticos e 20 (21,5\%) trabalhavam na construção civil. Com relação à renda média, 87 (89,6\%), recebiam até dois salários mínimos. Destes, 86 (92,4\%) eram aposentados ou pensionistas, com tempo médio de 9,5 anos (0-37).

Na Figura 1, constam dois quadros de quatro casas obtidos a partir dos termos indutores ( $A=$ pessoa ser idosa e $B=$ pessoa ser envelhecida $)$ apresentados de forma pareada, nos quais constam os cognemas evocados com suas respectivas frequências e a ordem em que foram evocados (OME) segundo os respectivos quadrantes.

Figura 1 - Quadro de quatro casas para os termos indutores "pessoa ser idosa" (A) e "pessoa ser envelhecida” (B). Juiz de Fora - MG, 2020.
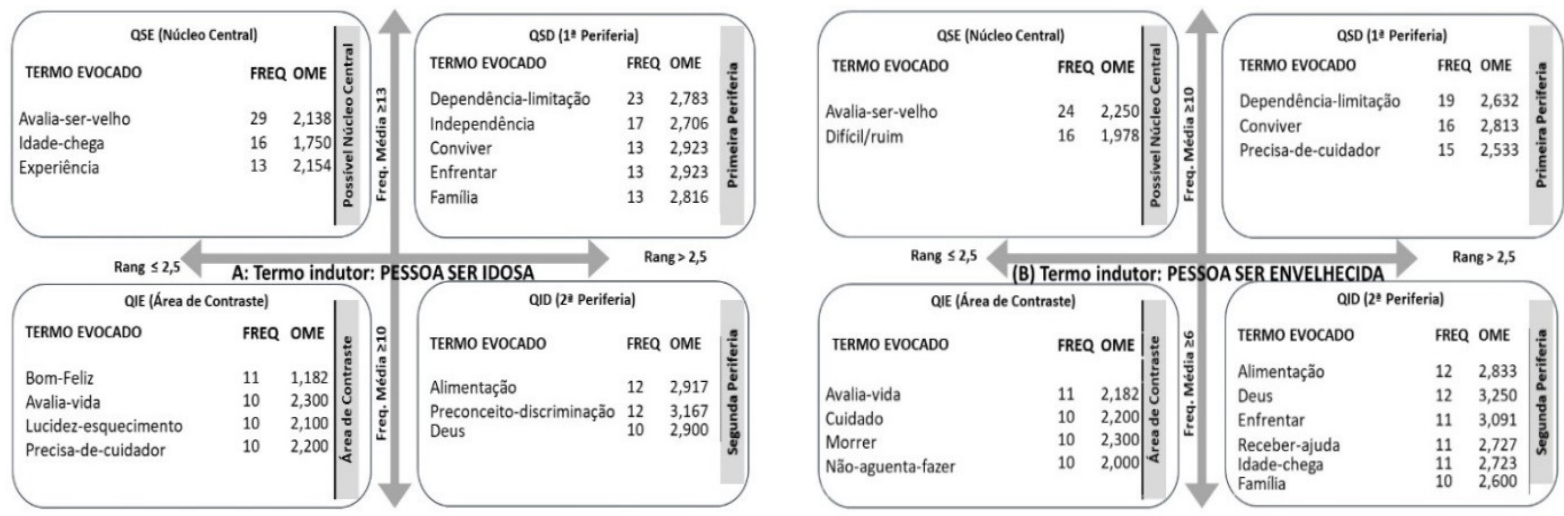

Nota: OME - Ordem Média de Evocações.

Fonte: Dados obtidos no Programa EVOC.

Foram obtidas duas categorias: 1) Expectativas de, apesar da idade, manter-se engajado, receber apoio e lidar com novas demandas e 2) Marcas advindas do tempo e limitações confirmadas (Figura 2). 
9 | Melo LD, Arreguy-Sena C, Gomes AMT, Parreira PMD, Pinto PF, Rocha JCCC

Figura 2 - Dendograma e gráfico de círculo que retratam as concepções dos participantes sobre ser idoso e ser envelhecido (N=93). Juiz de Fora- MG, 2020.

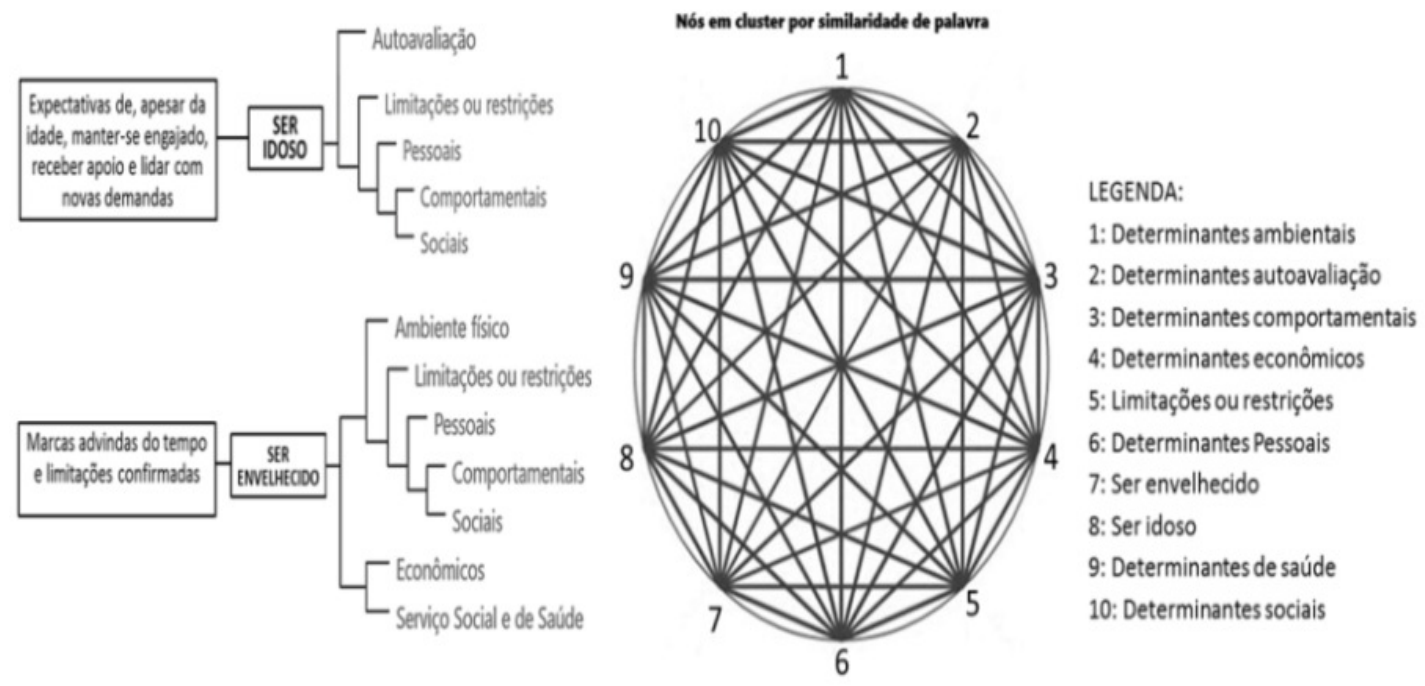

Fonte: software NVivoPro-11.

Na Figura 3, constam fragmentos de discursos obtidos pela abordagem processual que justificaram e corroboraram os conteúdos mencionados na abordagem estrutural. Foram utilizados como critério para selecioná-los aqueles que continham os cognemas mencionados e/ou parte de seus desdobramentos temáticos. Eles foram reunidos em eixos por similaridade e nomeados de: avaliação, engajamento, apoio, demanda e limitações valorativas. 
Figura 3 - Esquema comparativo exemplificando como os fragmentos discursivos (abordagem processual) retrataram os cognemas (abordagem estrutural) a ponto de gerar cinco categorias temáticas ao caracterizarem uma pessoa de acordo com os termos "pessoa ser idosa" e "pessoa ser envelhecida" (N=93). Juiz de Fora- MG, 2020.

\begin{tabular}{|c|c|c|c|}
\hline \multirow{2}{*}{\multicolumn{2}{|c|}{$\begin{array}{l}\text { Agrupamento de } \\
\text { Cognemas }\end{array}$}} & \multicolumn{2}{|c|}{ Fragmento de discurso obtido pela abordagem processual entre 93 sujeitos } \\
\hline & & Pessoa ser idosa & Pessoa ser envelhecida \\
\hline \multirow{5}{*}{ 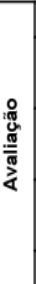 } & Avalia ser velho & 0 "ser velha" não é defeito! Não acho o velho problema! Acho quando ele fica doente. S02. & A gente perde a conta. Já não é como quando era nova. Tudo muda. S26 \\
\hline & Idade chega & $\begin{array}{l}\text { Bom, eles falam que pessoa idosa é a partir de } 60 \text { anos, o rádio mesmo fala que é assim [...] } \\
\text { Considera idoso após os } 60 \text { anos. } 551\end{array}$ & $\begin{array}{l}\text { Quando ela passou dos } 70 \text { anos, não adianta ela querer falar que é nova e isso ou aquilo. Não } \\
\text { tem este nem aquele. S10. }\end{array}$ \\
\hline & Avalia vida & $\begin{array}{l}\text { Eu vou ser sincero com você! Eu estou com esta idade de } 72 \text { anos, mas a minha disposição } \\
\text { continua a mesma... É a mesma de jovem... (risos). S14. }\end{array}$ & $\begin{array}{l}\text { Eu acho que cada tempo no seu tempo. Eu sei que eu já fui nova. Já fui menina e tudo. Fuil } \\
\text { evoluindo (risos). Mas, para mim, não mudou nada. S46. }\end{array}$ \\
\hline & Enfrentar & $\begin{array}{l}\text { Pessoa idosa é aquela que ainda quer ir além, ela pode estar ruinzinha, mas ela ainda quer } \\
\text { andar (risos). S84. }\end{array}$ & $\begin{array}{l}\text { A idade machuca um pouco a gente. Mas a gente não pode é parar. Quando não tem uma } \\
\text { atividade, você tem fazer outra coisa diferente. S28. }\end{array}$ \\
\hline & Morrer & Então são coisas que você tem que aceitar por que a velhice e a morte são inevitáveis. S03. & Eu acho que é só depois que ela morre. Acaba tudo quando você morre. S41. \\
\hline \multirow{3}{*}{ 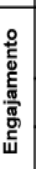 } & Experiência & $\begin{array}{l}\text { Ao longo dos anos, a gente vai convivendo com muitas pessoas e a gente aprende muito até } \\
\text { com as pessoas que são menos que a gente. } S 18 \text {. }\end{array}$ & $\begin{array}{l}\text { étem que ter valor o saber e experiência de vida. A pessoa já é velha. Se não fosse a gente ser } \\
\text { velho, o que seriam dos mais novos? S24. }\end{array}$ \\
\hline & Bom/feliz & Algumas coisas são diferentes, mas eu me sinto bem em ser uma idosa. S17. & Eu tenho 71 anos [...] Tem gente que fala: Nossa! Está com 70 anos só? Então, está bom. S45. \\
\hline & Independência & Eu ainda ando pra todo lado. Faço minhas coisas e não dependo de ninguém. S23. & \\
\hline \multirow{4}{*}{$\frac{\circ}{8}$} & Família & $\begin{array}{l}\text { A família ter uma pessoa idosa muda, porque ninguém tem paciência comigo aqui em casa... } \\
\text { Minha família não tem jeito. S16. }\end{array}$ & $\begin{array}{l}\text { Quando a pessoa é abandonada. Assim que não tem relação com a família. Ela não recebe o } \\
\text { mínimo de atencão ou as outras pessoas fazem pouco caso. S40. }\end{array}$ \\
\hline & Deus & Agradeço a Deus todos os dias pelo que ele me deu e pelo que ainda pode me dar. S15. & Uma pessoa idosa é uma bênção de Deus por ter chegado a esta idade. S16. \\
\hline & Alimentação & $\begin{array}{l}\text { Tem que reduzir a alimentacãão, porque, se a gente se alimentar demais, pode fazer mal [...] o } \\
\text { organismo que á está mais fraco, não digere direito o alimento. S11. }\end{array}$ & $\begin{array}{l}\text { o Cada um tem um tipo de alimentação. Faz parte e contribuem para que o envelhecimento seja } \\
\text { differente em cada pessoa. S12. }\end{array}$ \\
\hline & Receber ajuda & & $\begin{array}{l}\text { Tenho um filho e uma neta que moram comigo. Eles fazem uma faxina para mim de vez em } \\
\text { quando [...] Tem pessoas que passam muito trabalho e precisam de ajuda. S23. }\end{array}$ \\
\hline \multirow{3}{*}{ 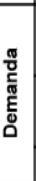 } & $\begin{array}{l}\text { Precisa de } \\
\text { cuidador }\end{array}$ & $\begin{array}{l}\text { Tem idoso que tem muita dificuldade porque ele depende muito do outro, às vezes de filho, } \\
\text { companheiro, de vizinho. S22 }\end{array}$ & $\begin{array}{l}\text { Uma pessoa envelhecida... Está prostrada em cima de uma cama, dependente a tudo. Ai } \\
\text { depende de uma pessoa para cuidar. S05. }\end{array}$ \\
\hline & Conviver & $\begin{array}{l}\text { E uma pessoa que precisa mais. Tem que respeitar a pessoa idosa, ter mais educação, saber } \\
\text { tratar eles, por causa da idade [... } 0 \text { idoso tem que ser bem tratado, bem aconselhado. SO6. }\end{array}$ & $\begin{array}{l}\text { A pessoa envelhecida é a pessoa que respeita a idade que ela tem. E sabe conversar com } \\
\text { todos, seja mais novo ou mais velho. S32. }\end{array}$ \\
\hline & Cuidado & & 0 cuidado da família tem que ser dobrado. Se todos forem sair de casa, um tem que ficar. S12. \\
\hline \multirow{5}{*}{ 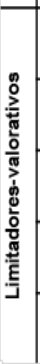 } & $\begin{array}{c}\text { Lucidez } \\
\text { esquecimento }\end{array}$ & $\begin{array}{l}\text { Eles acham que a gente está doida e não sabe de nada [...] Eu entendo tudo, por enquanto, eu } \\
\text { estou boa de cabeca. SO2. }\end{array}$ & $\begin{array}{l}\text { uGraças a Deus, eu ainda estou lúcida. Sei o que eu sei. } 0 \text { que eu posso falar e o que eu não } \\
\text { posso. S42. }\end{array}$ \\
\hline & $\begin{array}{l}\text { Dependência } \\
\text { limitação }\end{array}$ & $\begin{array}{l}\text { Eu acho que pela limitação de tudo que eu fazia antes... Esta modificação de vida não pode } \\
\text { assumir uma casa com todas as obrigaçôes... S82. }\end{array}$ & eUma pessoa envelhecida é aquela que já não fala e não ouve bem. S05. \\
\hline & $\begin{array}{l}\text { Preconceito } \\
\text { discriminação }\end{array}$ & Ás vezes, não contratam o idoso ou mandam embora só por causa da sua idade. S12. & Eu sinto pena das pessoas envelhecidas, conforme muitos sentem da gente. S17. \\
\hline & Difícil/ruim & $\begin{array}{l}\text { Ser idoso é muito ruim... A gente é muito abandonada, é muito fechado, é desprezado demais... } \\
\text { S34. }\end{array}$ & $\begin{array}{l}\text { Depender dos outros para tudo é muito dificil. A gente que está acostumada a fazer as coisas da } \\
\text { gente e andar pra todos os lados... S23. }\end{array}$ \\
\hline & $\begin{array}{l}\text { Não aguenta } \\
\text { fazer }\end{array}$ & & Não se tem mais força. Eu também já não aguento mais nada. S13. \\
\hline
\end{tabular}

Fonte: Fragmentos de dados extraídos do software Nvivo Pro-11.

\section{Discussão}

A predominância de mulheres na investigação (62,4\%), com idade média de 72 anos, aproxima-se da expectativa de vida da população brasileira que é de 76,2 anos. Assim como o fato de elas procurarem os serviços de saúde com mais frequência e adotarem hábitos saudáveis quando comparado aos homens. ${ }^{1} \mathrm{O}$ índice que representa a cor de pele declarada parda $(51,6 \%)$ foi superior ao da média nacional $(46,7 \%)$. Igualmente, ter em média quatro filhos diverge da realidade nacional, que é de 1,77. A baixa escolaridade dos participantes, de até oito anos $(88,1 \%)$, 
11 | Melo LD, Arreguy-Sena C, Gomes AMT, Parreira PMD, Pinto PF, Rocha JCCC

está em consonância com o perfil nacional das pessoas idosas, como também a profissão (serviços domésticos e construção civil) e a renda. ${ }^{1}$

A análise processual busca os processos constitutivos das representações sociais (objetivação e ancoragem), demonstrando a ligação entre pensamento e ação. Isso evidencia aspectos das atitudes (dimensão do afeto) e das informações que instruem as representações sociais; sendo, por isso, foco da discussão dos resultados..$^{5,7}$

$\mathrm{Na}$ abordagem estrutural, no QSE para “pessoa ser idosa” e “pessoa ser envelhecida”, surgiu o cognema "avalia-ser-velho" consensualizado para os termos indutores. O cognema a “idade-chega” tem caráter funcional, e “experiência” é um aspecto normativo associado ao engajamento vinculado ao fato de a pessoa ser idosa. O cognema "difícil-ruim" teve seu conteúdo ligado às limitações próprias do envelhecimento e esteve vinculado à condição de a “pessoa ser envelhecida”.

Isso porque o processo de envelhecimento humano pode cursar com comprometimentos cognitivos, deterioração emocional e redução de contatos sociais, e essa fase da vida é identificada com facilidade por aqueles que convivem com a pessoa idosa, mas nem sempre autopercebida. Isso se deve ao fato de as limitações serem graduais e haver dificuldade de reconhecê-las e aceitar o surgimento dos primeiros sintomas de incapacidade e/ou dependência, o que retrata a presença da síndrome da geriátrica, passível de ser prevenida/tratada, quando diagnosticada precocemente..$^{9,14-15}$

Essa síndrome cursa com alterações na autonomia (cognição e humor), independência, capacidade aeróbica, mobilidade, continência esfincteriana, estabilidade postural e capacidade para se comunicar. ${ }^{14-15}$ As pessoas idosas, ao se depararem com os primeiros indícios de limitação na funcionalidade, acessam conteúdos socialmente compartilhados e se comparam com o que consideram ser pessoas envelhecidas. ${ }^{9,15}$ A identificação de pelo menos uma das manifestações da síndrome geriátrica - reais, imaginárias ou potenciais - mostra-se suficiente 
para motivar um estado avaliativo e potencializar reflexões sobre fatos pregressos da vida, sobre a autoaferição de desempenho e afloração de sentimentos (aceitação, revolta, inconformação, indiferença ou acomodação diante das restrições progressivas do envelhecimento). ${ }^{14-15}$

$\mathrm{Na}$ primeira categoria da abordagem processual, intitulada "expectativa de, apesar da idade, manter-se engajado, receber apoio e lidar com novas demandas”, em análise do ponto de vista das representações sociais, encontram-se os elementos funcionais e os normativos. Os primeiros ("O ser velha não é defeito. Não acho velho um problema. Acho quando ele fica doente." S02) estão ligados às características descritivas ("Então, são coisas que você tem que aceitar porque a velhice e a morte são inevitáveis." S03) e às práticas que determinam as condutas dos sujeitos diante do objeto ('...] essa modificação de vida e não pode assumir uma casa com todas as suas obrigações". S82). Já os elementos normativos ( "Eu ainda ando para todo lado. Faço minhas coisas e não dependo de ninguém.” S23) constituem a dimensão social do

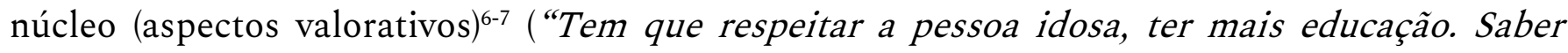
tratar eles por causa da idade [...]”S06).

O cognema “idade-chega”, componente do possível núcleo central para o termo indutor “pessoa ser idosa” e de segunda periferia para o termo "pessoa ser envelhecida”, remete a um marco cronológico, que delimita a idade a partir da qual a pessoa é classificada como idosa. Apesar de não haver um consenso no discurso dos participantes sobre a cronologia do envelhecimento, na análise do quadro de quatro casas, foi possível perceber que o grupo compreende, na perspectiva das informações contidas na abordagem processual, que ser idoso se refere a uma classificação da idade cronológica. Porém, ser envelhecido nem sempre está associado à idade, mas sim ao surgimento das características peculiares ao processo de envelhecimento.

O cognema "experiência", que consta do quadro de quatro casas, foi retratado na dimensão informativa. Ele pode estar vinculado ao saber social, ao conhecimento de vida, 
oportunizando o acesso a informações e seu compartilhamento a ponto de possibilitar uma reflexão sobre diferenças e semelhanças advindas das situações vivenciadas pelas pessoas com o decorrer dos anos em nível pessoal, familiar, profissional, social e religioso. ${ }^{16}$ Seu caráter valorativo positivo deveu-se à diversidade e ao enriquecimento vivencial advindos do contato intergeracional, agregado a valores, comportamentos, formas de pensar e de enfrentar as adversidades da vida. ${ }^{5,7}$

Os pontos de contato entre “ser idoso" e "ser envelhecido”, na categoria engajamento, possibilitaram emergir conteúdos sobre "experiência”, "bom-feliz" e "independência"; ou seja, componentes funcionais valorados como positivos. Isso porque, os participantes do grupo socialmente constituído nesta investigação afirmaram que os anos vividos foram capazes de lhes proporcionar um acúmulo de informações e conhecimentos aprendidos ao longo do tempo que desejam compartilhar com seus descendentes.

Nos demais quadrantes (QIE, QSD e QID), identificaram-se outros cognemas que foram comuns para a abordagem de ser idoso e ser envelhecido, tendo sido alocados em regiões hierárquicas distintas. Na área de contraste, QIE, para “pessoa ser idosa”, surgiram os cognemas: "bom-feliz", quando se sentem engajados socialmente; "avalia-vida”, decorrente de reflexões que fazem; "lucidez-esquecimento", como modificação que é marcadora do envelhecimento e "precisa-de-cuidador" como uma demanda.

A compreensão do processo de envelhecimento pode ser visto de forma antagônica à metáfora de Narciso - filho do Deus-rio Cephisus e da ninfa Liriope -, que, ao ver sua imagem no reflexo das águas de um lago, passou a dedicar horas na autocontemplação e análise de sua imagem em admiração. ${ }^{17}$ Esta metáfora pode ser aproximada ao comportamento de pessoas em processo de envelhecimento que se inspecionam com regularidade, buscando evidências da “envelhescência”. Isso por que, o surgimento das marcas de expressão e envelhecimento são 
fontes de tristeza, elas buscam por formas de retardar as modificações na aparência, em culto à juventude. $^{7}$

O cognema "lucidez-esquecimento", evocado para "pessoa ser idosa”, foi ancorado na imagem atribuída ao idoso pelo grupo sociofamiliar, a partir de restrições parciais ou totais que emergiram, percebidas durante o desempenho das Atividades de Vida Diária (AVDs) e/ou Atividades Instrumentais de Vida Diária (AIVDs). ${ }^{18}$ Esse cognema também remeteu à autoavaliação e à heteroavaliação sobre a transição da lucidez para o surgimento de lapsos de memória. $^{19}$

O cognema "bom-feliz", apresentado apenas para o termo indutor “pessoa ser idosa”, foi usado para exprimir sentimentos e ações. Nesse sentido, ele surgiu na acepção positiva, no adiamento da identificação das limitações ou na adaptação e aceitação dessa fase da vida. Um estudo com 3.750 pessoas, com idade entre 40 e 85 anos, identificou que tanto homens quanto mulheres apresentaram padrões semelhantes de satisfação global com a vida, mesmo considerando as mulheres com maior probabilidade de se tornarem viúvas e cônjuges cuidadoras quando comparadas aos homens. ${ }^{20}$

O termo “avalia-ser-velho”, primeira expressão do provável núcleo central para ambos os termos indutores, pode ser atribuído a valores positivos ou negativos. Ele foi mencionado associado às características próprias do processo de envelhecimento e relacionado com a imagem que o grupo social faz dos diferentes contextos: social, familiar, religioso e comportamental. Traduziu um posicionamento dúbio quanto ao teor valorativo frente ao objeto representado.

Na categoria intitulada "marcas advindas do tempo e limitações confirmadas", emerge a percepção depreciativa. Ela foi corroborada pelo termo “avalia-ser-velho" e remete ao processo de desengajamento e incapacidade para atividades de autocuidado. Reforça-se, assim, o valor social atribuído à participação ativa das pessoas na dinâmica da vida como elemento integrador 
15 | Melo LD, Arreguy-Sena C, Gomes AMT, Parreira PMD, Pinto PF, Rocha JCCC

das pessoas idosas na manutenção da saúde funcional e preservação da autonomia. ${ }^{17-18,20-21}$ Tal concepção também emergiu na abordagem processual, conforme exemplificado pelo fragmento de discurso “a gente perde a conta. Já não é como era nova. Tudo mudou”. (S26)

Os cognemas "difícil-ruim”, alocados no núcleo central, e “avalia-vida”; “cuidado”, “morrer” e "não-aguenta-fazer”, alocados no QIE, referentes a "pessoa ser envelhecida”, remeteram a situações ou circunstâncias de dependência ou inatividade, segregação, isolamento social ou abandono advindos das relações sociais e familiares. ${ }^{21-22} \mathrm{O}$ "cuidado" se associa à necessidade de acessar ou ter disponível uma rede de apoio social para viabilizar o atendimento das necessidades humanas e de interação, e a complexidade do cuidado remete ao reconhecimento de se dispor de sustentações físicas e psíquicas, quando o idoso não é capaz de realizar seu autocuidado. ${ }^{20-21}$

O cuidado esteve vinculado ao apoio familiar. O cognema “família” é de primeira periferia para o termo indutor "pessoa ser idosa" e de segunda periferia para "pessoa ser envelhecida”. Divino (“Deus”) e fisiológico (“alimentação”), alocados no QID para ambos os termos indutores, foram mencionados na concepção normativa e valorados positivamente, ligados à condição de receber ajuda. Já o cognema “morrer” resgatou a dimensão de finitude, numa perspectiva temporal, que antecede a aproximação da morte de modo a negá-la ou prorrogá-la. ${ }^{23}$

As pessoas idosas querem estar perto da família, em especial dos filhos, e a ausência de algum deles ocasiona sentimentos de: falta, abandono, desprezo, carência, tristeza e dependência por parte da pessoa envelhecida em relação à família. Isso porque as experiências das pessoas idosas por contato social, contexto intergeracional, meios de comunicação (individual e de massa), engajamento em atividades de lazer, trabalho ou recreação podem possibilitar o compartilhamento de comportamentos, atitudes, valores, imagens, informações e conhecimentos sobre como esse momento é e como ele é retratado por outras pessoas..$^{5-6}$ 
Representações sociais elaboradas por pessoas idosas sobre ser idoso ou... | 16

A alocação dos cognemas “alimentação” e "Deus” retrata posições individualizadas dos participantes em decorrência da falta de consensualização dos cognemas. Os cognemas “avaliavida” (QIE para ambos os termos indutores), “independência” (QSD para “pessoa ser idosa”), “conviver” (QSD para ambos os termos indutores), “enfrentar” (QSD para “pessoa ser idosa” e QID para “pessoa ser envelhecida”) ancoram o envelhecimento numa perspectiva de processo “ativo e bem-sucedido”. Vinculam-no à capacidade do idoso de estar fisicamente ativo; engajado; participativo; aceito; com vontade de viver; com autoestima, autonomia e funcionalidade preservadas e criativo, a ponto de reinventar formas de se inserir nos contextos social, econômico, familiar e cultural. ${ }^{18-19}$

A expressão “não-aguenta-fazer”, alocada na área de contraste para “pessoa ser idosa”, remeteu ao reconhecimento dos déficits gradativos advindos do envelhecer. Está vinculada à perda de forças, da capacidade e de motivação para se engajar nas AVDs e AIVDs, com reflexos na própria segurança e chances de ruptura dos vínculos sociais. Isso ocasiona o surgimento de situações de preconceito-discriminação entre grupos nos quais a convivência se alicerça no culto à independência e à juventude. ${ }^{18}$

A aproximação entre os conteúdos retratados nas abordagens estrutural e processual da TRS possibilitou a identificação dos elementos e processos constituintes de suas representações sobre "ser envelhecido" e "ser idoso". Observou-se que as pessoas idosas o fazem a partir de uma construção simbólica alicerçada na avaliação daquilo que observam nos indivíduos que estão no contexto social, comparando com as mudanças que o tempo gerou nelas.

Diante do exposto, os conteúdos mencionados permitem compreender que o processo de envelhecimento e o aumento da idade são condições que foram construídas socialmente de forma coerente com a imagem de uma sociedade capitalista. Nesta, a autoimagem precisa ser conservada e o surgimento de limitações é visto como uma condição desfavorável e indesejável. A imagem do envelhecimento pode estar ligada a incapacidades, menos-valia, além de não ser 
17 | Melo LD, Arreguy-Sena C, Gomes AMT, Parreira PMD, Pinto PF, Rocha JCCC

aceita como um processo natural, assim também a proximidade da morte é vista como algo indesejável.

Ao analisar comparativamente as concepções dos termos indutores “ser idoso" e "ser envelhecido”, foi possível identificar algumas aproximações entre eles, cuja interpretação difere quanto ao nível de consensualização de seus conteúdos segundo cada termo indutor. Isso pode ser exemplificado pelos cognemas “cuidador”, “avalia-vida”, “independência”, “conviver”, “enfrentar” e “família”.

Por isso, é possível dizer que as representações sociais apresentadas possuem implicações na concepção de como ocorre a vida cotidiana. Também possibilitam a compreensão de como o processo de envelhecimento e o aumento da idade são percebidos no grupo social investigado. ${ }^{10}$ Os elementos simbólicos e representativos identificados nesta investigação são marcantes e de caráter valorativo neutro ou de negação de um processo natural para o envelhecimento. Cabe, portanto, uma reflexão sobre quais estratégias poderão ser utilizadas pelo enfermeiro que atua na UBS para favorecer a inserção da pessoa idosa num contexto social no qual o que se valoriza é a juventude e a produtividade.

É necessário que o enfermeiro reflita sobre como sua conduta terapêutica poderá contribuir para a construção coletiva de ações que lidam com a "envelhescência”. Tal ação deve ocorrer por meio de valorização e de incentivo à participação e ao engajamento intergeracional e tecnológico de idosos. O objetivo terapêutico deve envolver a criação de oportunidades para o enfrentamento de manifestações da síndrome geriátrica, cargas de doenças e uso contínuo de medicações. Deve-se assegurar a busca por autonomia e independência dos idosos e promover o respeito a eles. Ressalta-se, ainda, a proteção e a valorização dos idosos numa sociedade que passa por redução significativa no número de descendentes e aumento da expectativa de vida. 


\section{Conclusão}

$\mathrm{Na}$ análise das representações sociais de pessoas com idade $\geq 65$ anos, verificou-se uma ausência de conteúdos objetivados no núcleo central, o que se justifica pelo fato de a sua origem estar ancorada em experiências próprias e com terceiros, vinculadas a nível de (in)dependência, condições de vida, apoio familiar e religião. Carreiam semelhanças/distinções que retratam a busca do idoso por se "categorizar" no contexto daquilo que concebe socialmente como sendo um idoso em processo de envelhecimento.

Houve consenso a respeito da "avaliação-de-ser-velho" para as representações sobre ser idoso ou envelhecido e cognemas similares foram alocados em posições hierárquicas diferentes no quadro de quatro casas para ambos os termos indutores. O caráter depreciativo esteve vinculado à perda da autonomia e da independência quando foi avaliado o envelhecimento. O aumento da idade emergiu como algo inadiável e cronológico, agregando experiência, requerendo apoio e gerando demandas quando vinculado às primeiras manifestações da síndrome geriátrica.

Espera-se que os conteúdos, estruturas e origens das representações, por retratarem como as pessoas com idade $\geq 65$ anos se percebem no processo de envelhecimento, subsidiem a reflexão de enfermeiros da atenção primária à saúde sobre o planejamento do cuidado para esse grupo social. As implicações para a prática do enfermeiro podem se traduzir em melhor compreensão de como os sujeitos sociais se percebem no processo de envelhecimento à medida que os anos passam, podendo repercutir um planejamento de cuidado que contemple a autoimagem e a autopercepção de viver com 65 anos ou mais.

O fato de o delineamento se dar pela TRS instiga a necessidade de investigar a temática do processo de envelhecimento em outros contextos sociais, a fim de evidenciar as concepções compartilhadas por eles e compreender o que há de aproximações ou distanciamentos com os resultados obtidos na presente investigação. 


\section{Referências}

1. Câmara dos Deputados (BR), Centro de Estudos e Debates Estratégicos, Consultoria Legislativa. Brasil 2050: desafios de uma nação que envelhece [Internet]. Brasília (DF): Edições Câmara; 2017 [acesso em 2019 set 12]. (Série Estudos Estratégicos; n. 8). Disponível em: https://www2.camara.leg.br/atividadelegislativa/comissoes/comissoes-permanentes/ce/noticias/brasil-2050-desafios-de-uma-nacao-queenvelhece

2. World Health Organization (WHO). Health statistics 2016: monitoring health for the SDGs sustainable development goals [Internet]. World Health Organization; 2016 [cited 2019 Sept 12]. Available from: https://www.who.int/gho/publications/world_health_statistics/2016/en/

3. United Nations (UN), Department of Economic and Social Affairs, Population Division. The world population situation in 2017 [Internet]. New York: United Nations; 2017 [cited 2019 Sept 12]. Available from: https://population.un.org/wpp/

4. Ministério da Saúde (BR), Secretaria de Ciência, Tecnologia e Insumos Estratégicos, Departamento de Ciência e Tecnologia. Agenda de prioridades de pesquisa do Ministério da Saúde - APPMS [Internet]. Brasília (DF): Ministério da Saúde; 2018 [acesso em 2019 set 12]. Disponível em: http://bvsms.saude.gov.br/bvs/publicacoes/agenda_prioridades_pesquisa_ms.pdf

5. Sá CP. Estudos de psicologia social: história, comportamento, representações e memória. Rio de Janeiro (RJ): EdUerj; 2015.

6. Abric JC. Prácticas sociales y representaciones. 13a ed. México (DF): Ediciones Coyoacán; 2013.

7. Moscovici S. Representações sociais: investigações em psicologia social. 11ª ed. Petrópolis: Vozes; 2015.

8. Aldwin C, Igarashi H, Gilmer D, Levenson MR. Health, illness, and optimal aging: biological and psychosocial perspectives [Internet]. 13 ${ }^{\text {th }}$ ed. Springer Publishing Company; 2017 [cited 2019 Sept 12]. Available from: https://www.springerpub.com/health-illness-and-optimal-aging-third-edition9780826134042.html

9. Uchmanowicz I, Jankowska-Polańska B, Wleklik M, Lisiak M, Gobbens R. Frailty syndrome: nursing interventions. SAGE Open Nurs. 2018;4:1-11. doi: https://doi.org/10.1177/2377960818759449

10. Melo LD. O processo de envelhecimento para pessoas idosas: estudo de representações sociais e crenças de Rokeach [dissertação]. Juiz de Fora: Universidade Federal de Juiz de Fora; 2015. 189 p.

11. Janczura GA, Castilho GM, Keller VN, Oliveira, NR. Free association norms for 1004 Portuguese words. Psicol Teor Pesqui. 2017;32(5):669-84. doi: https://doi.org/10.1590/0102-3772e32ne23

12. Wachelke J, Wolter R, Matos FR. Efeito do tamanho da amostra na análise de evocações para 
Representações sociais elaboradas por pessoas idosas sobre ser idoso ou... | 20

representações sociais. Liberabit. 2016;22(2):153-60. doi: https://doi.org/10.24265/liberabit.2016.v22n2.03

13. Bardin L. Análise de Conteúdo. Lisboa: Edições 70; 2016. 280 p.

14. Tabue-Teguo M, Simo N, Lorenzo N, Rinaldo L, Cesari M. Frailty syndrome among elderly in Caribbean Region. J Am Med Dir Assoc. 2017;18(6):547-8. doi: https://doi.org/10.1016/j.jamda.2017.03.009

15. Vaughan CP, Markland AD, Smith PP, Burgio KL, Kuchel GA; American Geriatrics Society/National Institute on Aging Urinary Incontinence Conference Planning Committee and Faculty. Report and research agenda of the American Geriatrics Society and National Institute on Aging Bedside-to-Bench Conference on urinary incontinence in older adults: a translational research agenda for a complex geriatric syndrome. J Am Geriatr Soc. 2018;66(4):773-82. doi: https://doi.org/10.1111/jgs.15157

16. Cruz A, Tosoli-Gomes AM, Parreira PM, Oliveira DC. Traducción y adaptación transcultural del hospitalized elderly needs awareness scale (henas) para la lengua portuguesa (Brasil y Portugal). Aquichan. 2017;17(4):425-36. doi: https://doi.org/10.5294/aqui.2017.17.4.6

17. Oliveira M. Reflexos de Narciso: traços do arquétipo mítico-psicanalítico nos selfies. Ciberlegenda [Internet]. 2015 [acesso em 2019 set 12];32:83-94. Disponível em: https://periodicos.uff.br/ciberlegenda/article/view/36977/21552

18. Blomgren C, Jood K, Jern C, Holmegaard L, Redfors P, Blomstrand C, et al. Long-term performance of instrumental activities of daily living (IADL) in young and middle-aged stroke survivors: results from SAHLSIS outcome. Scand J Occup Ther. 2018;25(2):119-26. doi: https://doi.org/10.1080/11038128.2017.1329343

19. Peixoto RI, Silveira VM, Zimmermann RD, Gomes AM. End-of-life care of elderly patients with dementia: a cross-sectional study of family carer decision-making. Arch Gerontol Geriatr. 2018;75:83-90. doi: http://dx.doi.org/10.1016/j.archger.2017.11.011

20. Hansen T, Slagsvold B. The age and subjective well-being paradox revisited: a multidimensional perspective. Nor Epidemiol. 2012;22(2):187-95. doi: https://doi.org/10.5324/nje.v22i2.1565

21. Klinga C, Hasson H, Sachs MA, Hansson J. Understanding the dynamics of sustainable change: a 20year case study of integrated health and social care. BMC Health Serv Res. 2018;18(1):400. doi: https://doi.org/10.1186/s12913-018-3061-6

22. Baker S, Warburton J, Waycott J, Batchelor F, Hoang T, Dow B, et al. Combatting social isolation and increasing social participation of older adults through the use of technology: a systematic review of existing evidence. Australas J Ageing. 2018;37(3):184-93. doi: https://doi.org/10.1111/ajag.12572

23. Andrade LAS, Santos SP, Corpolato RC, Willig MH, Mantovani MF, Aguilera AL. Elderly care in the emergency department: an integrative review. Rev Bras Geriatr Gerontol.2018;21(2):243-53. doi: https://doi.org/10.1590/1981-22562018021.170144 


\section{Autor correspondente}

Laércio Deleon de Melo.

E-mail: laerciodl28@hotmail.com

Endereço: Rua Doutor Dirceu de Andrade, $n^{\circ}$ 201, apartamento: 305, Bairro: Dom Bosco, Juiz de Fora, Minas Gerais (MG), Brasil

CEP: 36025-330.

\section{Contribuições de Autoria}

\section{1 - Laércio Deleon de Melo}

concepção e planejamento do projeto de pesquisa, obtenção ou análise e interpretação dos dados, redação e revisão crítica.

\section{2 - Cristina Arreguy-Sena}

Concepção e planejamento do projeto de pesquisa, obtenção ou análise e interpretação dos dados, redação e revisão crítica.

\section{3 - Antônio Marcos Tosoli Gomes}

Redação e revisão crítica.

\section{4 - Pedro Miguel Dinis Parreira}

Redação e revisão crítica.

\section{5 - Paulo Ferreira Pinto}

Concepção e planejamento do projeto de pesquisa, redação e revisão crítica.

\section{6 - Júlio Cézar Cruz Collares da Rocha}

Redação e revisão crítica.

\section{Como citar este artigo}

Melo LD, Arreguy-Sena C, Gomes AMT, Parreira PMD, Pinto PF, Rocha JCCC. Representações sociais elaboradas por pessoas idosas sobre ser idoso ou envelhecido: abordagens estrutural e processual. Rev. Enferm. UFSM. 2020 [Acesso em: Anos Mês Dia]; vol.10 e53: 1-21. DOI:https://doi.org/10.5902/2179769238464 